\title{
Commentary: Are worse clinical outcomes (after transcatheter aortic valve replacement) associated with red blood cell transfusion? The chicken or the egg dilemma
}

\author{
Davide Pacini, MD, PhD, and Giacomo Murana, MD
}

\author{
From the Cardiac Surgery Unit, S. Orsola Hospital, University of Bologna, Bologna, Italy. \\ Disclosures: Authors have nothing to disclose with regard to commercial support. \\ Received for publication April 22, 2019; accepted for publication April 22, 2019; available ahead of print June 8, \\ 2019. \\ Address for reprints: Davide Pacini, MD, PhD, Cardiac Surgery Unit, S. Orsola Hospital, University of Bologna, \\ 40128 Bologna, Italy (E-mail: davide.pacini@unibo.it). \\ J Thorac Cardiovasc Surg 2020;159:114-5 \\ $0022-5223 / \$ 36.00$ \\ Copyright $@ 2019$ by The American Association for Thoracic Surgery \\ https://doi.org/10.1016/j.jtcvs.2019.04.073
}

Transfusion of red blood cells (RBCs) is a common practice in cardiac surgery and is often considered a poor prognostic factor. However, a causal relationship with worse outcomes has not been demonstrated in observational studies and randomized controlled trials because patients receiving $\mathrm{RBC}$ transfusion tend to be sicker and have a greater disease burden. ${ }^{1,2}$ What we face here is the question of which comes first, the chicken (patient condition) or the egg (transfusion factor).

In this noteworthy retrospective study of 12,187 patients, the authors extracted data from the National Impatient Sample database to determine the rates, temporal trends, and independent predictors of RBC transfusion in patients undergoing transcatheter aortic valve replacement (TAVR) in the United States. ${ }^{3}$ They divided the population into 2 groups-patients who received RBC transfusions and patients who did not-and examined the association between RBC transfusion and in-hospital outcomes. ${ }^{3}$

The authors present a realistic picture of the TAVR momentum reporting for 3 relevant reasonable certainties:

- RBC transfusion (after propensity matching) was associated to an increased risk of in-hospital mortality, infection, and transient ischemic attack/stroke in patients with no bleeding, but not in those with overbleeding. Hence, what seems to be implied is that transfusion in patients without bleeding may be secondary to a sicker population with underlying coexisting disease such as frailty, malnutrition, anemia of chronic disease, and subclinical bleeding diathesis (ie, arteriovenous malformations common in aortic stenosis) not accounted for in the propensity matching, with expected poor post-TAVR outcomes.

- Endovascular TAVR is the preferred way to perform this procedure. To be completely percutaneous without the intrinsic invasiveness of a surgical procedure minimizes

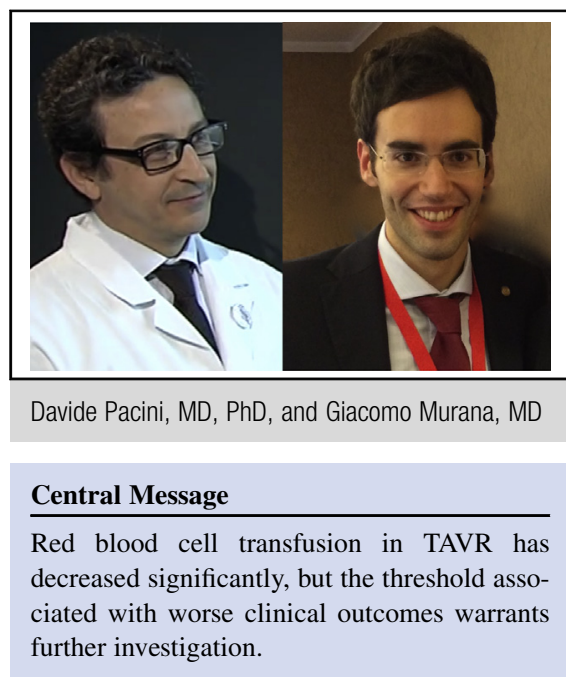

See Article page 102. the risk of bleeding events and related postoperative complications (eg, infections and respiratory impairment) compared with transapical access.

- The increase in procedural experience along with the introduction of smaller sheaths, and a diminishing reliance on the transapical approach, contributed to the reduction in rates of $\mathrm{RBC}$ transfusion from $29.5 \%$ to $10.8 \%$ during the study period. A similar trend was confirmed by the Society of Thoracic Surgeons/ American College of Cardiology Transcatheter Valve Therapy Registry during the same time period. ${ }^{4}$

The authors should be commended for their organized and focused analysis of a recognized issue in cardiac surgery. They brilliantly delineate the profile of patients with severe aortic stenosis undergoing TAVR and the way this relates to in-hospital outcomes regardless of RBC transfusions. Unfortunately, uncertainty on the variable and complex relationship between transfusion and outcomes still persists because patient factors, operation-related factors, and institutional factors remain unmeasured confounding conditions on retrospective studies. However, Kolte and colleagues ${ }^{3}$ deserve credit for their work showing that as well as minimizing $\mathrm{RBC}$ transfusion, improved patient outcomes, reduced costs, 
and conserved blood in patients undergoing TAVR was observed. Therefore, saving both the chicken and the egg could represent an initial condition to further investigate this dilemma.

\section{References}

1. Patel NN, Murphy GJ. Evidence-based red blood cell transfusion practices in cardiac surgery. Transfus Med Rev. 2017;31:230-5.
2. Hajjar LA, Vincent JL, Galas FR, Nakamura RE, Silva CM, Santos MH, et al. Transfusion requirements after cardiac surgery: the TRACS randomized controlled trial. JAMA. 2010;304:1559-67.

3. Kolte D, Beale C, Aronow HD, Kennedy KF, Apostolidou E, Sellke FW, et al. Trends and outcomes of red blood cell transfusion in patients undergoing transcatheter aortic valve replacement in the United States. J Thorac Cardiovasc Surg. 2020;159: 102-11.e11.

4. Grover FL, Vemulapalli S, Carroll JD, Edwards FH, Mack MJ, Thourani VH, et al 2016 Annual report of the Society of Thoracic Surgeons/American College of Cardiology Transcatheter Valve Therapy Registry. J Am Coll Cardiol. 2017;69:1215-30. 